\title{
Notes on the vocalizations of White-winged Brush-finch (Atlapetes leucopterus)
}

Peter Boesman

In the following we briefly analyze and compare voice of the three races of White-winged Brushfinch (Atlapetes leucopterus). We also try to quantify the extent of any vocal differences using the criteria proposed by Tobias et al. (2010), as a support for taxonomic review. We have made use of sound recordings available on-line from Xeno Canto (XC).

Race paynteri: song typically starts with 1-2 introductory notes followed by a note repeated 3-6 times.
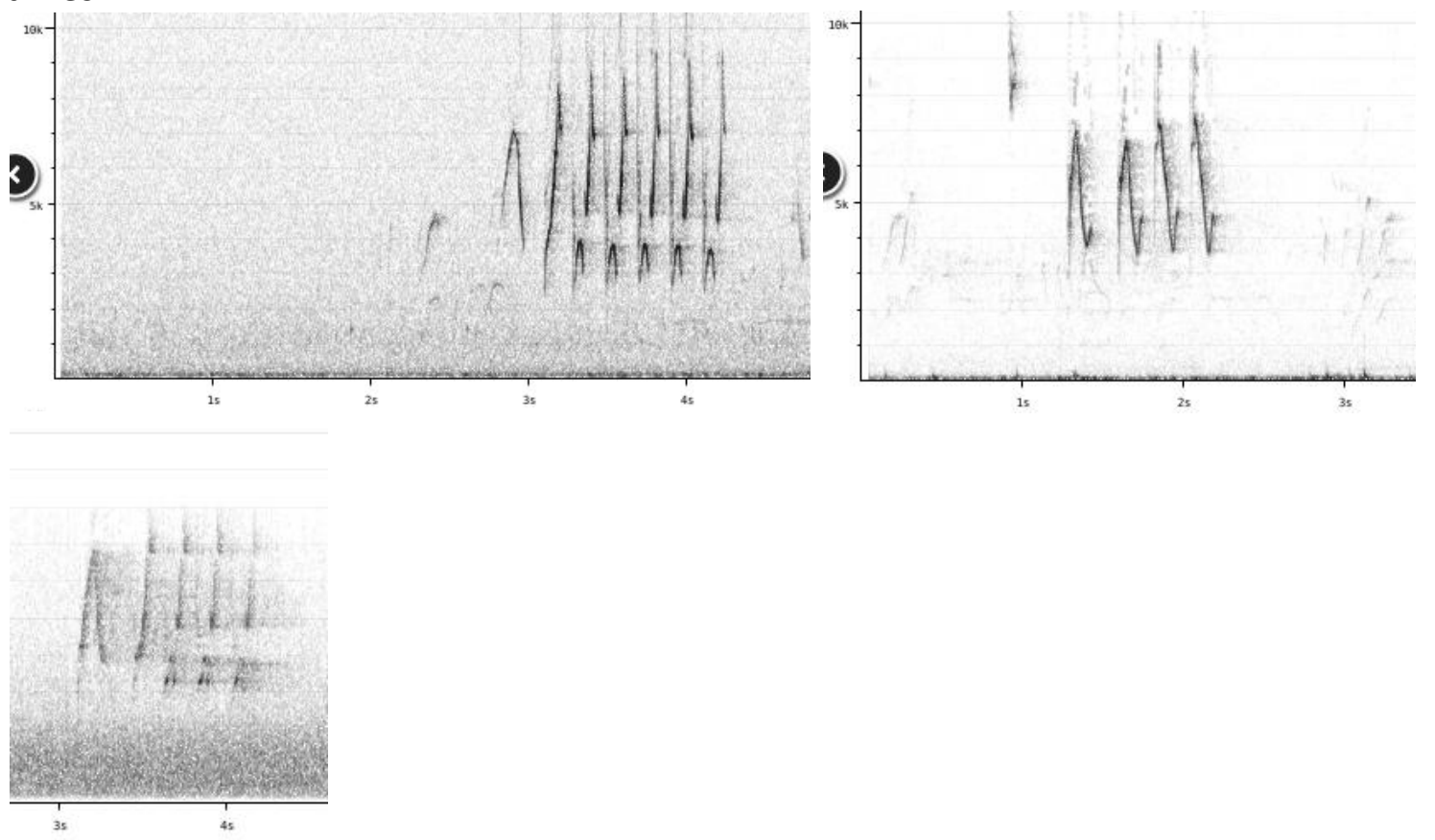

To be compared with other races:

Race dresseri:

Race leucopterus:
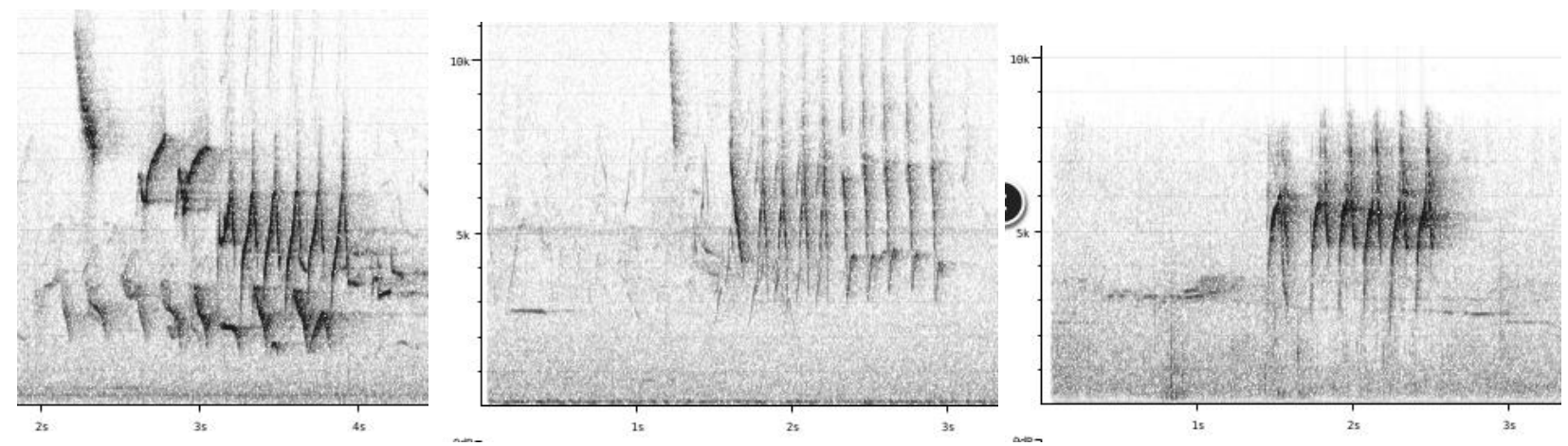
Song of all races is structurally similar.

paynteri seems to have on average less notes per phrase with notes which are repeated at a slightly slower pace, but there are very few recordings of song available for all taxa, so this is nothing more than an indication of a possible vocal difference.

This note was finalized on 25 h May 2016, using sound recordings available on-line at that moment. We would like to thank in particular the sound recordists who placed their recordings for this species on XC:

\section{References}

Tobias, J.A., Seddon, N., Spottiswoode, C.N., Pilgrim, J.D., Fishpool, L.D.C. \& Collar, N.J. (2010). Quantitative criteria for species delimitation. Ibis 152(4): 724-746.

\section{Recommended citation}

Boesman, P. (2016). Notes on the vocalizations of White-winged Brush-finch (Atlapetes leucopterus). HBW Alive Ornithological Note 366. In: Handbook of the Birds of the World Alive. Lynx Edicions, Barcelona. (retrieved from http://www.hbw.com/node/1252913 on 2 November 2016). 